\title{
A CURADORIA NO PINTEREST COMO TRANSCRIAÇÃO DA REPRESENTAÇÃO E DO IMAGINÁRIO ACERCA DO ÁTOMO
}

\author{
Tatiana Zarichta Nichele Eichler, PPG em Educação em Ciências - UFRGS \\ tatizneichler@gmail.com
}
Ione Canabarro de Araújo, PPG em Educação em Ciências - UFRGS ionecanabarroaraujo@gmail.com
Marcelo Leandro Eichler, PPG em Educação em Ciências - UFRGS exlerbr@gmail.com

\begin{abstract}
Resumo
A curadoria pode ser entendida como uma metáfora do processo de ensino. Novos recursos de compartilhamento de ideias visuais em redes sociais, como o Pinterest, facilitam processos de curadoria e de ensinagem. Neste artigo, discutimos a curadoria no Pinterest em seu aspecto de transcriação didática e focamos a discussão em um dos mais tradicionais conteúdos curriculares do ensino de física e de química, o modelo atômico. Nesse sentido, a transcriação didática do átomo é apresentada em seu potencial de representação e de imaginação.
\end{abstract}

Palavras-chave: curadoria, transcriação, redes sociais, natureza do átomo

\section{THE CURATING IN THE PINTEREST AS TRANSCREATION OF THE REPRESENTATION AND THE IMAGINARY ABOUT THE ATOM}

\begin{abstract}
Curating can be understood as a metaphor of the teaching process. New resources for sharing visual ideas on social networks, such as Pinterest, must facilitate curating and teaching processes. In this article, we discuss the curating on Pinterest in its aspects of didactic transcreation, for this we focus the discussion in one of the most traditional curricular contents of the science teaching, the atomic model. In this sense, the didactic transcreation of the atom is presented in its potential of representation and imagination.
\end{abstract}

Keywords: curating, transcreation, social network, nature of the atom

\section{Introdução}

As redes sociais são agora um marco da vida cotidiana. Embora muitos recursos ainda possam mudar, atualmente estamos vivendo em tempos em que aplicativos de mídia social, como Facebook, Twitter, Tumblr, Snapchat, Pinterest e Reddit, estão amplamente disseminados e são muito populares (Selwyn e Stirling, 2016).

Justamente por isso, se pode dizer que aprender através de mídias sociais digitais está se tornando cada vez mais atual, moderno, rápido, eficiente e pode ocorrer em qualquer lugar, não necessariamente dentro de uma sala de aula. Sites de mídias sociais são, indiscutivelmente, acessíveis fora da sala de aula através de desktops, computadores portáteis, tablets, mas as evidências em relação ao uso de telefones móveis, smartphones, têm grande influência na aprendizagem dos alunos. Esta aprendizagem móvel tem lugar em uma variedade de conformações, como no ônibus, no restaurante, na fila do banco, enquanto se trabalha em outro computador. À medida que 
esta aprendizagem móvel também possa ser colocar dentro da sala de aula está começando a ser explorada (Tavares et al., 2013).

Como é possível verificar a partir na análise do potencial para a educação do Facebook (Canabarro e Basso, 2013) ou do Tumblr (Paula e Camelo, 2012), é notório que há muito tempo a Revista Novas Tecnologias na Educação tem sido um espaço privilegiado para a reflexão acadêmica sobre a utilização das redes sociais no contexto da educação e do ensino de diversas disciplinas. Nesse sentido, como pretendemos demonstrar neste artigo, o Pinterest é um poderoso recurso auxiliar ao processo criativo, de ensinagem e de transcriação didática.

No âmbito da museografia, a utilização do Pinterest para a curadoria tem sido recentemente abordada em temas diversos como, por exemplo, a história da astronomia (Owens, 2016) ou a antropologia (Pearce e Learmonth, 2013). Já do ponto de vista educacional, diversos professores têm adotado o Pinterest para uso no ensino e aprendizagem conceitual onde, por exemplo, se pode explorar o valor pedagógico da rede social como plataforma multimídia para ser usada tanto dentro quanto fora da sala de aula (Nogueira e Pereira, 2015). Na união dessas duas áreas, na próxima secção, buscamos discutir a transcriação, em que o processo de curadoria é subentendida como metáfora da ensinagem.

\section{A transcriação como etapa/fim da curadoria}

A curadoria é o processo de organização, cuidado e montagem de uma exposição artística, formada por um conjunto de obras de um ou de vários artistas, a partir da seleção prévia feita pelo curador. O trabalho de um curador atinge não apenas os bens materiais do mercado da arte, mas também possui um importante compromisso educacional na sociedade, agindo como um mediador cultural entre a arte e a população que visita às exposições. Por isso, o curador é, também, um educador.

A utilização do Pinterest como ferramenta de curadoria na educação ou no ensino escolar pode ser antecedida de reflexões sobre a própria natureza da educação, do ensino e da aprendizagem. Por exemplo, como podemos desenvolver didáticas a partir de um objeto, uma música, um pedaço de plástico, uma fórmula matemática ou um passo de dança? (Corazza, 2013)

Mas a pergunta é: na área da Educação, como pensar o ensino em termos de processos de criação? Qual é a especificidade da atividade criadora do professor/educador/curador? E nesse enfoque criacionista, o que o Currículo e a Didática criam? O que caracteriza seus atos de criação? $O$ que acontece quando o professor/educador/curador tem uma ideia? Em que consistem os meandros e limites de criar didáticas? (Corazza, 2015) Afinal, o que é criar didáticas? Como se dão as ações de ver, falar, escrever, interpretar e traduzir de forma didática? Em que medidas necessitamos de outros processos, por exemplo, os literários, os cinematográficos, musicais, científicos ou filosóficos? Essas e inúmeras outras questões implícitas nesse contexto todo são respondidas internamente, inconscientemente quando pensamos em preparar uma aula, como fazer para que os estudantes prestem atenção no professor/educador/curador, no que ele está explicando, demonstrando, exibindo, dialogando.

Para isso, o professor/educador inevitavelmente deve estar intimamente ligado à imaginação, ao processo criativo para ter sucesso em sala de aula; e fora também. Simples assim. Simples assim? É mesmo? E como se faz isso? Como melhorar, fazer nascer, exercitar, se empoderar do processo criativo? Professores/educadores/curadores movimentam, orquestram, concertam, articulam, ensaiam seus processos de pesquisa, criação e inovação, acolhendo e honrando os elementos científicos, filosóficos e 
artísticos possivelmente extraídos de obras já realizadas, que outros autores criaram, em outros planos, tempos e espaços. E isso é errado? É cópia? É plágio? É imitação? Não. Inspiração, incentivo quem sabe?!

O processo de tradução, mais especificamente, que incide no processo de criação e expressa por encontros entre formas de conteúdo e de expressão do mundo sensível, histórico e linguístico, pois ao educar, os professores, educadores, nós nos apropriamos dessas formas, desafiando as línguas que as produziram e liberando-as dos meios que as articularam, que as detém. Os tradutores, porém, cultivam traços dos elementos originais e os transformam, agenciam, ajustam, conduzem, orientam de maneiras singulares. Além disso, os próprios processos tradutórios do mundo, da vida, das culturas, do currículo, da didática só podem funcionar com relação ao plano empíricotranscendental da invenção, que conecta o tempo cronológico e o tempo aiônico do acontecimento.

Seguindo nesse ensejo, o professor-tradutor-intérprete desenvolve experimentações, que desconstroem o existente, transgridem as circunscrições sígnicas e rompem com a relação aparente entre teoria e prática; portanto, em cada professor, habita um autor, constituído por jogadas inventivas, que tumultuam a linguagem da educação, escava outra língua nas matérias originais, levando-as a sofrer, por sua vez, reviravoltas. Por isso, os procedimentos tradutórios implicam mais do que transportar ou transladar os sentidos de uma língua para outra, já que os elementos vertidos são sempre transcriados.

O trabalho intelectual dos professores, pensado como um processo tradutório transcriador, oferece o seu método de jogo de dados - antagônico aos modos reacionários de pensar a profissão, que dominam as premissas acerca da imagem aviltada do professor (Corazza, 2016). Certamente há outras redes sociais visuais que poderiam ser utilizadas para o mesmo fim de transcriação, como Flickr, o Instagram e o Tumblr, entretanto o espectro de infografias, representações e obras de arte são muito superiores no Pinterest. Os pinboards podem ser desenvolvidos com foco nas necessidades dos alunos, por exemplo, como um suplemento para leitura adicional, e em segundo lugar, como um recurso de revisão antes de provas, avaliações, exames. Nas próximas secções buscamos mostrar a utilização didática do Pinterest na transcriação de um conteúdo exemplar da educação científica, o modelo atômico de partículas.

\section{Desenvolvimento e Resultados}

O Pinterest permite que o usuário, qualquer um, aluno ou professor, seja curador dos assuntos de seu interesse, realizando alguma seleção, classificação e mediação do assunto em curadoria para uma audiência possível, mais ou menos ampla, como suporte teórico e metodológico. Ou seja, com o Pinterest é possível formar um ambiente, um cenário para que haja um processo de criação de uma didática a partir de um tema, uma obra, um artista, uma disciplina, um filme, uma imagem etc.

Em termos metodológicos, este trabalho foi desenvolvido com enfoque heurístico para classificar as imagens e ou infográficos, buscando chegar a distinguir aquelas que poderiam ser consideradas narrativas, ou seja, aquelas imagens que contam histórias. (Ferrer, 2015). A exploração heurística inicial dos infográficos e das imagens de obras de arte, dentro e fora do Pinterest, revelou uma grande variedade formal e temática de recursos. Para dirimir esta variedade através de uma amostra representativa, a pesquisa foi realizada a partir de um perfil de usuário no Pinterest para coligir, compilar, recompilar, juntar, armazenar imagens conhecidas ou pins de infografias $\mathrm{e}$ visualizações. 
A partir do quadro geral do aplicativo, o usuário pode gerenciar as imagens a serem coletadas, agrupando por tema comum e exibir em quadro de anúncios online. Cada usuário pode compartilhar suas imagens, recompartilhar as de outros utilizadores e colocá-las em suas coleções ou quadros (pinboards), além de poder comentar e realizar outras ações disponibilizadas pelo site. Para que os usuários possam interagir de uma forma mais ampla com outras comunidades, o site é filiado com o Twitter, Facebook e Skype.

Atualmente o Pinterest trabalha com um novo e complexo algoritmo baseado na qualidade do seu pin, na qualidade do site/blog de origem do pin e numa classificação atribuída pelo próprio aplicativo. A qualidade do pin tem a ver com a quantidade de interações que ele recebe (repins). Ele é movido para o topo do feed e permanece por lá enquanto estiver recebendo repins. A qualidade da fonte é determinada pela frequência com que os pinners (usuários) frequentemente compartilham conteúdo de um determinado site ou blog. A classificação realizada pelo Pinterest é uma avaliação da performance, do desempenho de cada pin com critérios exclusivos e comparativos com outros pins da mesma fonte.

A ideia do funcionamento deste algoritmo é proporcionar uma ótima seleção dos conteúdos na página, no perfil de cada usuário, não somente com base na novidade, mas também de sua relevância, característica relacionada com a combinação de variáveis de interações básicas (vistas, repins, cliques, comentários, etc.), a sua popularidade e como com histórias semelhantes de um comportamento do usuário específico, incluindo os seus dados demográficos.

No smart feed, o Pinterest coloca em primeiro plano os pins melhor ranqueados e não os mais recentes. Dessa forma, é necessário estar atento a essas regras para maximizar nosso desempenho na rede. De acordo com o blog do Pinterest, os "melhores pins" são imagens de alta qualidade, claras e relevantes, que contenham pouquíssimas palavras e que incluam descrições úteis e generosas. Logicamente, tudo corre através de um processo em tempo real muito rápido vai escolhendo o mais adequado, utilizando modelos de regressão logística e redes neurais, entre outros, predizendo com alta precisão as publicações que podem ser de interesse do utilizador. O desenvolvimento é dinâmico e vai se alimentando com novas interações, bem como as melhorias feitas pela equipe técnica do Pinterest e com isso, o usuário certamente encontrará uma forma mais "de seu acordo", a cada próxima vez que acessar o Pinterest.

Assim, devido ao conhecimento dessas características do Pinterest, o processo de curadoria que passamos a mostrar nas secções seguintes foi realizado em um período de tempo estendido, por cerca de um mês.

\subsection{A curadoria da representação do átomo}

Atualmente a representação icônica do átomo vai além de sua reconstrução histórica padrão, que descreve o modelo grego de Demócrito e Leucipo, o modelo de Dalton, o modelo de Rutherford, a correção de Bohr para esse modelo e um modelo quântico. A partir do modelo de Rutherford, o primeiro que contém um núcleo, busca-se agregar as partículas atômicas, relacionando as interações de atração e de repulsão entre nêutrons, prótons e elétrons. Porém, agora o átomo é descrito de forma mais complexa, onde são agregadas novas e menores partículas. O Modelo Padrão de Partículas é ele mesmo um tema de pesquisa científica na atualidade.

$\mathrm{Na}$ educação em ciências, particularmente no ensino de física, há quem defenda a inclusão de temas contemporâneos na educação escolar em nível médio. Por exemplo, Moreira (1989) indica que nos anos 1980 houve um movimento de físicos estadunidenses que solicitaram uma reformulação curricular nacional da física do ensino 
médio visando justamente incluir a apresentação de temas contemporâneos de ciências na escola básica. Entre os temas que podem ser abordados na Física Moderna e Contemporânea está a física das partículas elementares, que subjaz a apresentação do Modelo Padrão de Partículas. Existem pesquisas no âmbito do ensino de física (Pinheiro, 2011; Siqueira e Pietrocola, 2012) que tem buscado mostrar as potencialidades e dificuldades da inclusão desse tema na educação escolar em nível médio. Entre as potencialidades se pode destacar o interesse pela própria complexidade e pela inovação, o que envolveria um pouco a sedução da diferença, a motivação do irregular. Sobre as dificuldades, reiteram-se os problemas de formação de professores e da disponibilidade de recursos didáticos.

Cabe destacar que existem bons e extensos recursos didáticos preparados especificamente para professores de física e de química sobre a temática (Ostermann, 1999; Abdalla, 2005). Entretanto, acredita-se que os recursos da cultura digital e do design da informação podem contribuir para a elaboração de materiais didáticos mais atrativos, visuais e sintéticos para os professores e alunos (Mello e Boll, 2014).

Dessa forma, uma vez que o Pinterest é autodefinido como um Catálogo Mundial de Ideias, buscou-se verificar os recursos digitais ali presentes sobre o Modelo Padrão de Partículas. A ênfase envolveu encontrar, selecionar e compilar os recursos visuais que pudessem ser utilizados em transcriação da representação do átomo.

A coleta de imagens no Pinterest foi executada durante três semanas, entre março e abril de 2017. A quantidade de imagens encontradas está descrita e organizada na Tabela 1.

No momento da pesquisa na rede, vários pins eram mostrados como resultado da busca pelas palavras-chaves, entretanto, nem todos estavam relacionados especificamente com o tema proposto. Assim foi necessário para fazer uma seleção entre os pins encontrados, agrupando-os entre descartados, correlatos e adequados.

Entre os pins descartados se encontravam representações de modelos atômicos, colisões de partículas, equações da física quântica, spin e raios cósmicos, por exemplo. Entre os pins correlatos se verificou, na maioria dos casos, representações e esquemas explicativos sobre o Bóson de Higgs, uma específica partícula mediadora prevista no Modelo Padrão de Partículas que foi tema recente em diversas reportagens de divulgação científica. Por fim, entre os pins adequados foram considerados aqueles que exibiam sinteticamente as partículas elementares ou o Modelo Padrão de Partículas.

Tabela 1. Resultados das buscas dos pins para a representação do modelo padrão de partículas.

\begin{tabular}{|c|c|c|c|c|}
\hline \multirow{2}{*}{ Palavras-chaves } & Pins Totais & $\begin{array}{c}\text { Pins } \\
\text { Descartados }\end{array}$ & $\begin{array}{c}\text { Pins } \\
\text { Correlatos }\end{array}$ & $\begin{array}{c}\text { Pins } \\
\text { Adequados }\end{array}$ \\
\hline \multirow{3}{*}{ Modelo padrão de partículas } & 62 & 50 & 6 & 6 \\
\cline { 2 - 5 } & 60 & 48 & 6 & 6 \\
\cline { 2 - 5 } & 90 & 47 & 17 & 26 \\
\hline \multirow{3}{*}{ Partículas elementares } & 59 & 55 & 3 & 1 \\
\cline { 2 - 5 } & 75 & 63 & 7 & 5 \\
\cline { 2 - 5 } & 76 & 64 & 7 & 5 \\
\hline \multirow{3}{*}{ Partículas elementares - Física } & 150 & 117 & 18 & 15 \\
\cline { 2 - 5 } & 133 & 74 & 32 & 27 \\
\cline { 2 - 5 } & 63 & 40 & 12 & 11 \\
\hline \multirow{3}{*}{ Modelo padrão de partículas - Física } & 58 & 49 & 3 & 6 \\
\cline { 2 - 5 } & 58 & 44 & 6 & 8 \\
\cline { 2 - 5 } & 83 & 44 & 14 & 25 \\
\hline
\end{tabular}

Entretanto, observou-se entre os pins adequados uma grande variedade de conteúdo informativo. Nesse sentido, buscamos realizar algum tipo de análise do 
próprio conteúdo da imagem, de seu potencial de representação. A análise iconológica empregada para trabalhos com imagens, em princípio pareceu apropriada para este estudo, pois grande parte dos pins encontrados poderia ser classificada como imagens icônicas. Segundo Vicente (2000), esta metodologia se fundamenta em três níveis de significados das artes figurativas: "o primário, onde consta a identificação e descrição das formas; o secundário ou convencional, que atesta os motivos artísticos com base em textos e documentos elucidativos, e o terceiro que é o da análise propriamente, sendo aquela que desvenda os valores simbólicos das obras e de sua época". Entretanto, observou-se que a análise iconológica é mais apropriada para obras de arte, cinema, fotografia e imagens publicitárias.

Também se especulou a possibilidade de usar a análise generalizada de planos na infografia em meio digital como recurso para categorizar os pins encontrados. Segundo Canabarro (2015), as fotografias e a infografia podem ser lidas e analisadas por meio de planos. Assim, propõe-se o estudo em uma sequência de planos: i) primeiro plano, ii) plano de detalhes, iii) plano de fundo, e iv) plano geral. Porém, novamente esse método não nos pareceu adequado. A metodologia proposta por Canabarro (2015) é específica para imagens registradas em fotografias, neste sentido, não apropriada para ser empregada na análise dos pins coletados.

Perante essas dificuldades encontradas, no sentido de não encontrar uma metodologia e categorias para classificar e analisar os dados encontrados, optamos por criar nossos critérios de análise. Assim, realizamos uma análise de conteúdo por categorização emergente. Reconhecemos a importância da análise de conteúdo em se conjunto de técnicas de análise das comunicações, que visam obter por procedimentos sistemáticos e objetivos de descrição o conteúdo das mensagens, indicadores que permitam a inferência de conhecimentos relativos às condições de produção/recepção destas mensagens (Bardin, 2011). Nesse sentido, optou-se por elaborar as categorias que abrangesse o material selecionado na rede Pinterest levando em consideração o design empregado nos infográficos, conforme a Tabela 2.

Tabela 2. Categorias dos pins sobre modelo padrão de partículas encontrados no Pinterest.

\begin{tabular}{|c|l|c|}
\hline Categoria & \multicolumn{1}{|c|}{ Descrição } & Características \\
\hline \multirow{5}{*}{ Icônico } & $\begin{array}{l}\text { Figuras como cubo, esferas e outros formatos representam } \\
\text { os elementos básicos que formam a matéria. O cubo em } \\
\text { analogia aos tijolos estruturais, as esferas como pontos } \\
\text { geométricos perfeitos (elementares). Os diversos formatos } \\
\text { referem-se a um zoológico (The Particle Zoo), cada } \\
\text { particular elementar é representada por uma figura diferente, } \\
\text { por exemplo, o quark up tem forma de um triangulo } \\
\text { isósceles. }\end{array}$ & $\begin{array}{c}\text { Léptons, hádrons e } \\
\text { posons blocos e cores } \\
\text { diferentes. }\end{array}$ \\
\hline \multirow{3}{*}{ Formação } & $\begin{array}{l}\text { Partindo de partículas elementares ocorre a união para } \\
\text { formarem outras partículas, tais como prótons, nêutrons, } \\
\text { átomos, moléculas e estruturas maiores. }\end{array}$ & $\begin{array}{c}\text { Não apresenta } \\
\text { regularidades, pode } \\
\text { ser sequencial ou não. }\end{array}$ \\
\hline & $\begin{array}{l}\text { Tendo como referência uma partícula aceita historicamente } \\
\text { como estrutura da matéria, por exemplo, o núcleo atômico } \\
\text { com prótons e nêutrons, ocorre à divisão em partículas } \\
\text { consideradas elementares atualmente. }\end{array}$ & $\begin{array}{c}\text { Segue uma } \\
\text { sequência. }\end{array}$ \\
\hline
\end{tabular}

Empregando a análise de conteúdo a partir das categorias que constam na Tabela 2, os pins foram selecionados e classificados. Dessa forma, entre o total de 44 pins considerado adequados para apresentar a representação do Modelo Padrão de Partículas:

- 27 apresentam o design icônico (ou seja, 61\%);

- 8 apresentam ênfase na estrutura formativa, que chamamos de design de formação (ou seja, 18\%); e 
- 9 apresentam ênfase na "desmontagem" do átomo, até atingir a parte elementar da matéria, em um tipo de design que chamamos de design de fragmentação (ou seja, 21\%).

Na Figura 1 são apresentadas imagens de cada um desses tipos de infográficos sobre o Modelo Padrão de Partículas.

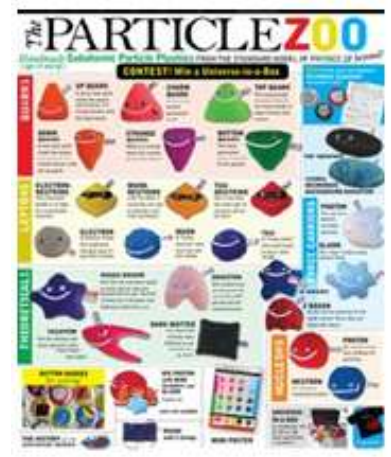

(a)

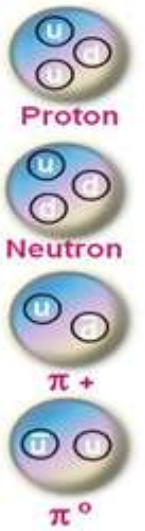

(b)

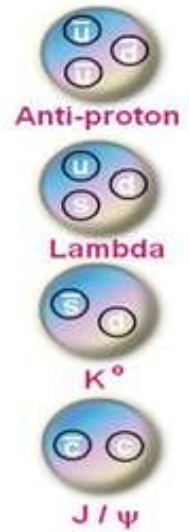

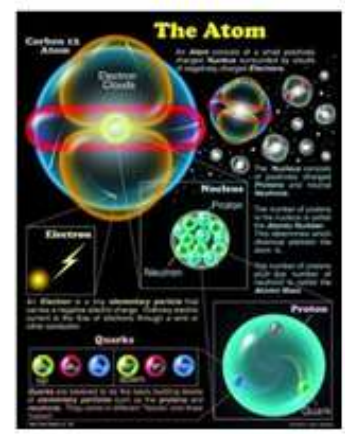

(c)

Figura 1. Categoria dos infográficos encontrados no Pinterest sobre modelo padrão de partículas: (a) formato icônico (cubo, esfera, formato diverso); (b) partículas elementares formando outras partículas ou estruturas; (c) fragmentação da matéria até o indivisível de hoje.

$\mathrm{Na}$ categoria Icônico, 13 pins representaram as partículas elementares como cubos agrupados, dando a ideia de tijolos ou blocos básicos da matéria. Uma analogia com a construção civil, os tijolos ou blocos de concreto são elementos fundamentais na construção de uma casa, um prédio comercial ou residencial, uma creche, por exemplo. Assim a partir das partículas elementares agrupadas seriam formados os hádrons (prótons, nêutrons) e sucessivamente os átomos, as moléculas, os tecidos e outras vivas ou inanimadas. $\mathrm{Na}$ mesma categoria, 11 pins representaram essas partículas como esferas ou como pontos geométricos perfeitos, considerados sem dimensão. Também com design icônico foram classificados 3 pins que faziam alusão ao "zoológico" de partículas proposto de pela designer Julie Peasly (veja https://www.particlezoo.net/).

$\mathrm{Na}$ categoria Formação foram encontrados 8 pins, todos eles apresentam representações de partículas elementares agrupadas, reunidas ou confinadas num espaço para formar outra partícula. O termo 'confinado' parece ser o mais apropriado quando abordamos partículas subatômicas. A teoria da matéria hadrônica, chamada cromodinânica quântica (quantun cromodynamics, em inglês), considera que é impossível obtermos quarks livres. A interação forte entre os quarks é atrativa e aumenta com a distância, assim quanto mais tentarmos separar os quarks, mais energia será necessária. Esta propriedade é conhecida como confinamento dos quarks.

Finalmente, na categoria Fragmentação foram agrupados 9 pins coletados e considerados adequados. O design dos pins dessa categoria segue outro padrão: partindo de uma partícula socialmente aceita como constituinte da matéria (o átomo, por exemplo) ocorre a separação, a divisão em partes menores até chegar no indivisível conhecido atualmente. Em termos pedagógicos, consideramos ser mais apropriado esse tipo design de infográfico para ser usado com alunos que estão aprendendo sobre o assunto partículas elementares, pois parte do conhecimento eventualmente já construído, facilitando uma abordagem construtivista ou significativa da aprendizagem do tema. 
Os vários pins adequados encontrados foram compilados e o recurso didático criado no processo de curadoria, conforme Figura 2, pode ser acessado no Pinterest: https://br.pinterest.com/ionecanabarroar/modelo-padrão-de-partículas ensino-físicaquímica/.

๑

( Q Pesquisar

\section{ث \\ Modelo Padrão de Partículas_ensino física/química}
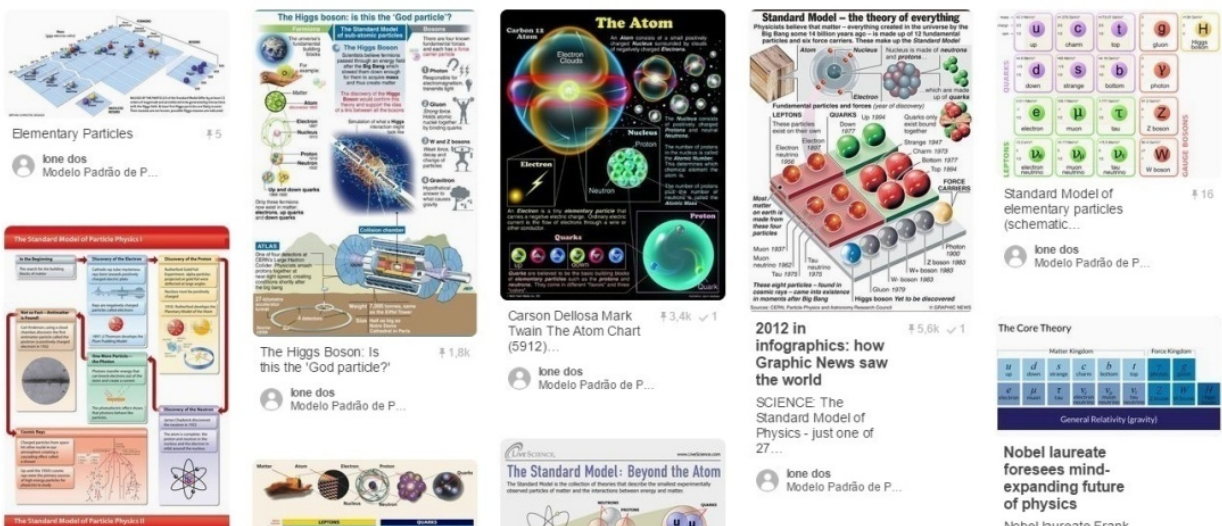

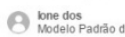
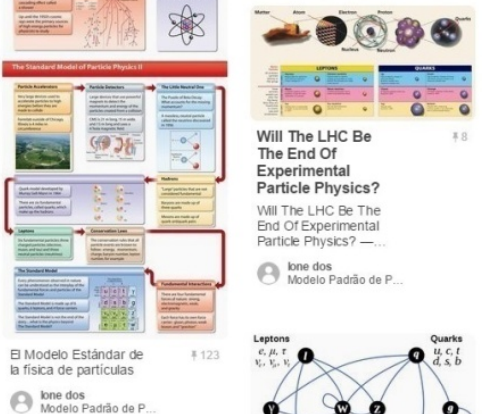

The End of

Particle Physics?

Wil The LHC Be The
End of Experimental
Particle Physics? -

8 be dos
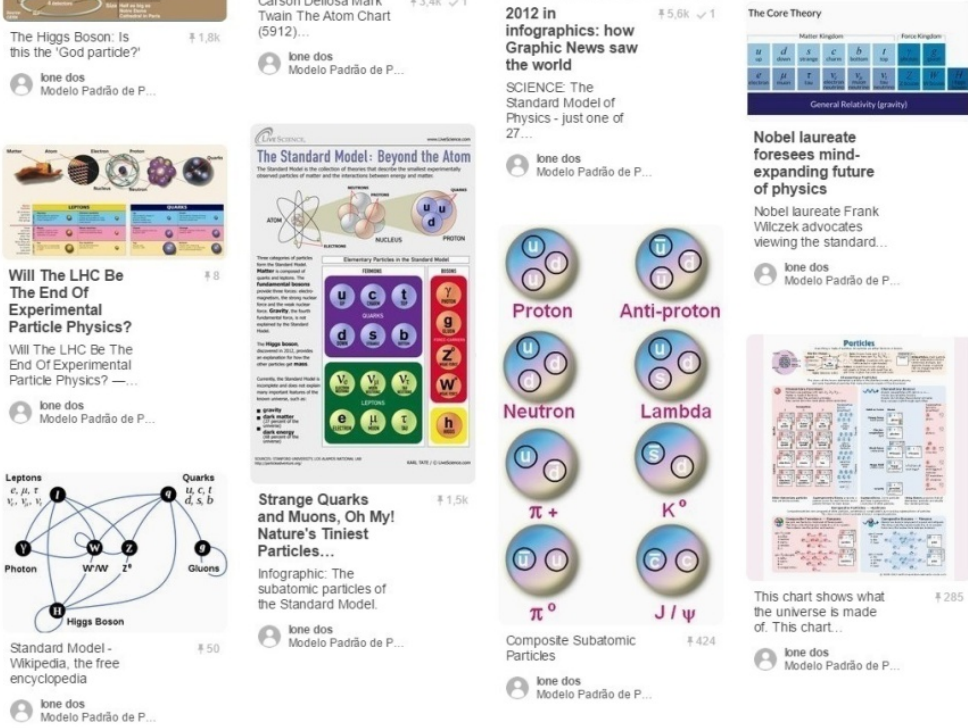

Nobel laureate
foresees mindexpanding future

Nobel laureate Frank
Wilczek advocates
viewing the standard

$\mathrm{A}_{\text {lone dos }}^{\text {bod }}$ Padito

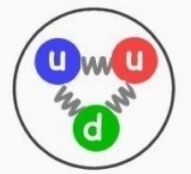

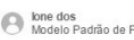

Q bre dos

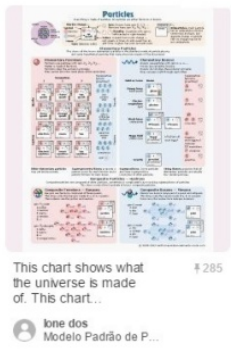

Figura 2. Pasta do Pinterest sobre infografia do Modelo Padrão de Partículas.

Na conclusão dessa parte do trabalho, pode-se verificar que o Pinterest é local digital usado para compartilhar e distribuir infográficos e vídeos, com grande potencial de ser utilizado na educação em ciências. Nessa arena digital são várias as pessoas construindo coletivamente conhecimento. Sob perspectivas diferentes surgem outros gráficos, são realizadas novas sínteses, o conhecimento é transcriado. A ecologia de informações e cognitiva tem um maior enfoque na imagem, na representação, mais do que no texto. As múltiplas formas de ver e tratar um tema, no caso específico desse trabalho sobre as partículas elementares, podem ser enriquecidas e mesmo aclaradas durante a navegação pelos recursos visuais presentes no Pinterest. Nesse sentido, indica-se aos professores de ciências (particularmente, aos de física e de química) que se inspiram na rede Pinterest para selecionar as representações dos conceitos científicos, para reelaborar seu material didático, enfim, para transcriar suas práticas educativas. 


\subsection{A curadoria do imaginário/imaginação do átomo}

A utilização de imagens relacionadas às artes traz uma possibilidade que vai além do passo inicial da pré-abstração referente à introdução de novos conceitos. As pinturas artísticas de diversos períodos históricos podem ser utilizadas como um ambiente de reflexão aprofundado das relações entre diferentes áreas do conhecimento (Gorri e Santin Filho, 2009). Nesse sentido, a curadoria que passamos a relatar a seguir tem relação com uma pesquisa interdisciplinar que visou uma aproximação entre as artes plásticas e o ensino de química, a partir do imaginário surrealista e surracionalista do átomo nucleado (Eichler, 2016).

A tradição de índole cartesiana parte do princípio que a imaginação é considerada como fundamentalmente reprodutora, ou seja, a imaginação tinha por função formar imagens que se impunham como cópias do real anteriormente percebido. Nesse sentido, a faculdade de imaginar era considerada subalterna, não só em relação à percepção, como, também, em relação à inteligência A percepção, por seu lado, permitiria apreender, através dos sentidos, com toda a força impactante da presença, o real que está diante de nós, dos olhos, palpável, ao alcance; a inteligência, por outro lado, conseguiria revelar, através dos conceitos, a verdadeira face do mundo. Diante disso, pode-se levar em consideração que, segundo a tradição, a imagem resultante da faculdade de imaginar era sempre algo inferior em termos do conhecimento do real. (Paiva, 2005).

Bachelard inaugura uma perspectiva original ao procurar estudar a imagem a partir de um enfoque estético. Para ele, a imagem não deve ser apreendida, como uma construção subjetiva sensório-intelectual, nem como uma representação mental fantasmática, fantástica, irreal, mas sim como um acontecimento objetivo integrante de uma imagética, ou seja, que se consegue exprimir através de imagens como evento de linguagem (Bulcão, 2013).

A fenomenologia da imaginação (Bachelard, 1989) instrui, ensina, sugere que cada um, em seu próprio âmbito de trabalho, que desrealizam a natureza para poder logo transcender o real, uns mediante a abstração, o devaneio, a fantasia de palavras e cores, outros mediante devaneios matemáticos, mas, e isso é o mais importante, ambos sob o mesmo desejo de imaginar, sob o mesmo poder sintético hominizante, antropológico da metaforização, antropológico da divinação, antropológico da metaforização daliniana, assim dizendo.

A pesquisa dos recursos visuais no Pinterest sobre o imaginário surrealista do átomo nucleado envolveu a criação de uma gama de pins relacionados com a parte do Misticismo Nuclear de Salvador Dalí, sendo coletados semanalmente durante um mês. Estes pins foram coligidos em uma pasta no Pinterest.

Inicialmente, a busca no Pinterest por determinadas palavras-chaves com relação à fase do Misticismo Nuclear não foram seletivas. Ou seja, quando foram utilizadas as palavras-chaves "Salvador Dalí Nuclear", "Salvador Dalí Misticismo", "Salvador Dalí Misticismo Nuclear" foram apresentadas inúmeras imagens, tantas que ficou inviável contar, calcular todas elas. Foram mais de 700 pins que o Pinterest selecionou para a busca para cada uma das palavras-chaves mencionadas anteriormente e como a contagem dos pins se faz manualmente, considerou-se que a análise seria exaustiva e pouco eficiente para o objetivo deste trabalho. Por esse motivo as palavras-chaves utilizadas nas buscas tiveram que conter mais expressões de seleção para que a busca pudesse ser restritiva e não tão abrangente.

Na Tabela 3 estão classificados em quatro categorias todos os pins encontrados no Pinterest com aquelas palavras-chaves selecionadas. São apresentados três conjuntos 
de dados uma vez que a coleta foi realizada em semanas sucessivas, entre outubro e novembro de 2016.

Tabela 3. Resultados das buscas dos pins para o imaginário do átomo em Salvador Dalí.

\begin{tabular}{|c|c|c|c|c|}
\hline Palavras-chaves & $\begin{array}{c}\text { Pins } \\
\text { Totais }\end{array}$ & $\begin{array}{c}\text { Pins } \\
\text { Descartados }\end{array}$ & $\begin{array}{c}\text { Pins } \\
\text { Correlatos }\end{array}$ & $\begin{array}{c}\text { Pins } \\
\text { Adequados }\end{array}$ \\
\hline \multirow{3}{*}{ Salvador Dalí, Crítico, Paranóico } & 72 & 18 & 53 & 1 \\
\cline { 2 - 5 } & 123 & 31 & 84 & 8 \\
\cline { 2 - 5 } & 124 & 33 & 83 & 8 \\
\hline \multirow{2}{*}{ Salvador Dalí, Fase Mística } & 127 & 45 & 72 & 10 \\
\cline { 2 - 5 } & 177 & 64 & 104 & 9 \\
\cline { 2 - 5 } & 179 & 61 & 110 & 8 \\
\hline \multirow{2}{*}{$\begin{array}{c}\text { Salvador Dalí, Misticismo Nuclear, } \\
\text { Percepção }\end{array}$} & 38 & 5 & 25 & 8 \\
\cline { 2 - 5 } & 89 & 17 & 59 & 13 \\
\cline { 2 - 5 } Salvador Dalí, Misticismo Nuclear, & 89 & 19 & 55 & 15 \\
\cline { 2 - 5 } Representação & 87 & 21 & 54 & 0 \\
\cline { 2 - 5 } & 88 & 19 & 56 & 13 \\
\hline
\end{tabular}

Os Pins Totais são referentes à totalidade de pins encontrados com as palavraschaves elencadas, os Pins Adequados são referentes às imagens das obras de acordo com as palavras-chaves elencadas, ou seja, pertencentes ao período do Misticismo Nuclear, os Pins Descartados são todos os pins em formato de vídeos e/ou fotografias e os Pins Correlatos são imagens correlatas, por exemplo, imagens do surrealismo de Salvador Dalí não pertencentes ao Misticismo Nuclear ou imagens de outros pintores surrealistas ou imagens de outros pintores inspirados nas obras de Dalí relacionados ou não ao Misticismo Nuclear.

Com relação aos dados obtidos na Tabela 3, pode-se observar que a diferença entre os Pins Adequados e os Pins Totais é grande, ou seja, mesmo que se faça uma busca por palavras-chaves acertivas, o número de pins com a característica, propósito, finalidade desejada se restringe muito. Há todo o trabalho de garimpo frente a variedade de opções que nos são apresentadas.

No entanto, mesmo com a redução de pins, o resultado final pode ser muito interessante porque cada pin abre uma gama de possibilidades, cada pin proporciona a inserção em um outro conjunto de pins, um outro pinboard onde o usuário poderá se perder em um labirinto de possibilidades, já que elas são muitas, e essa dimensão de possibilidades seguramente envolve o êxito em realizar a curadoria, uma vez que envolve o estudo e a transcriação.

O recurso didático criado no processo de curadoria pode ser acessado no Pinterest: $\quad$ https://br.pinterest.com/tatianazneichle/misticismo-nuclear-salvador-dalí (Figura 3), e se destina (ou pode se destinar) aos alunos, e também aos professores, a tarefa, o convite, a incumbência de realizar seu próprio conjunto de objetos visuais (curadoria) com os quais auxiliarão a construir sua própria aprendizagem (ou ensinagem), seus próprios subsídios para sanar a curiosidade e adquirir conhecimento. 
๑
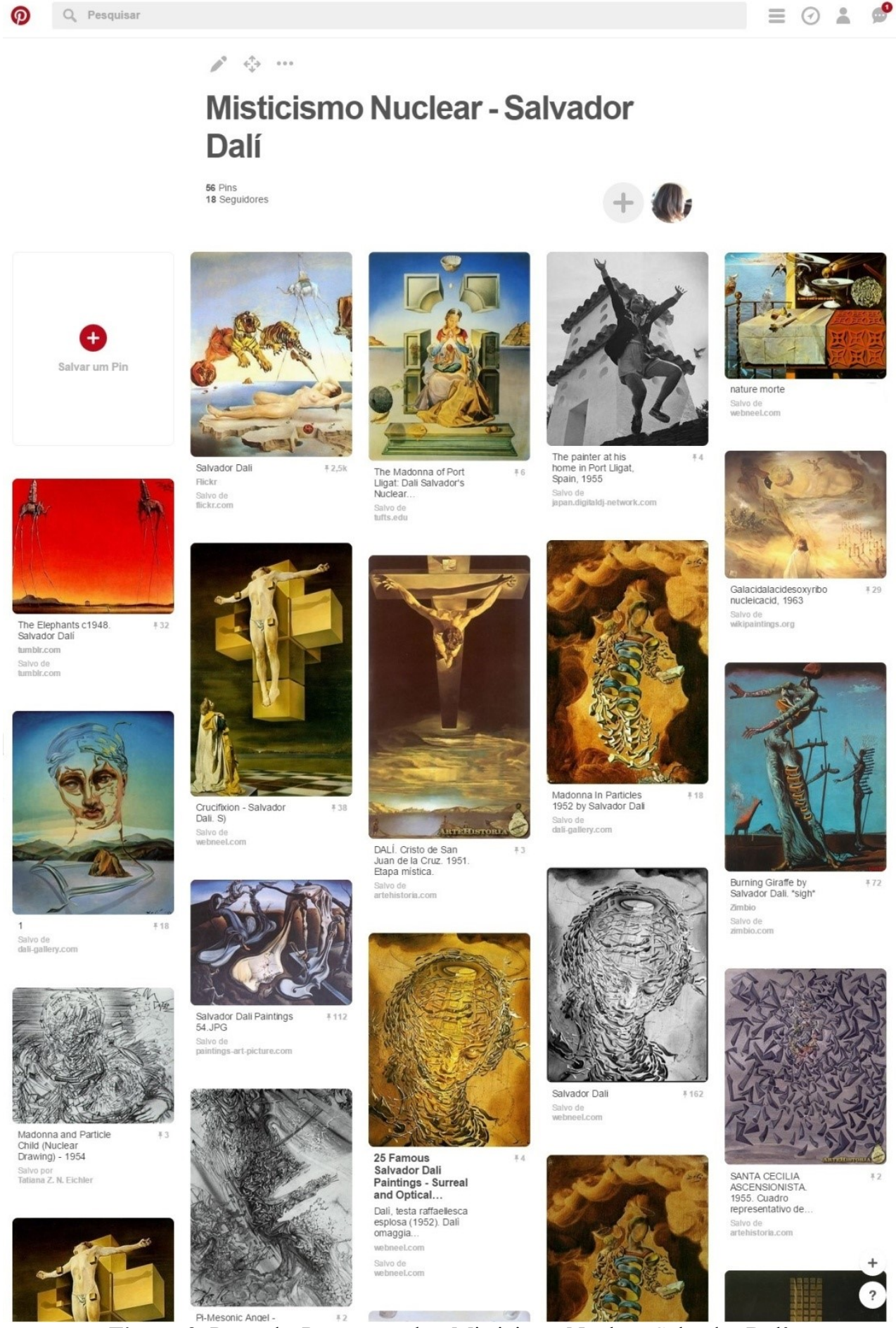

Figura 3. Pasta do Pinterest sobre Misticismo Nuclear-Salvador Dalí.

O resultado dessa curadoria é apresentado e discutido em Eichler (2016), em uma pesquisa de cunho interdisciplinar que envolveu a relação da educação química com as artes plásticas, o tem sido enaltecido em trabalhos recentes, seja no âmbito da didática das ciências, seja na filosofia da química. Nesse sentido, as pinturas de Salvador Dalí foram selecionadas com a intenção da variação do "enxergar", de um convite frente às novas interpretações para conhecimentos e tecnologias científicas, particularmente aquelas que se relacionam com a percepção e o imaginário da matéria em sua natureza atômica. 


\section{Considerações finais}

O Pinterest se mostrou uma ferramenta bastante promissora na formação, criação de uma curadoria que possibilite, proporcione ou evidencia a transcriação, o acúmulo de material para poder ser utilizado da melhor forma futuramente. A busca por uma variação do "enxergar" é um convite frente às novas interpretações para conhecimentos e tecnologias científicas, particularmente aquelas que se relacionam com a percepção e a representação da matéria em sua natureza atômica. Visando uma fissura do senso comum, da opinião cômoda academicista, propomos uma forma de trabalho que não fosse classificada como ingênua ou subjetiva. A literatura nos fornece o fundamento para usar novos recursos de distribuição de imagens para a produção de materiais didáticos que envolvam processos de curadoria, entendida aqui como uma metáfora do processo de ensino.

No entanto, a pesquisa visual de transcriação é um processo que demanda tempo para que o usuário (professor, aluno ou curioso) possa realizar a seleção de pins adequados para o determinado fim, já que a busca por palavras-chaves também fornece uma expressiva quantidade de pins que não se adéquam aos fins didáticos propostos.

Além disso, em relação às opções do Pinterest para classificar e gerir estes pins, sua utilização revela: i) pontos fortes: habilidade de armazenar grande número de elementos, para salvar as URLs de referências e ter uma ideia rápida do conteúdo de cada pin ao exibir as imagens-chave em cada board; e ii) pontos fracos: ausência de subgrids ou subboards, ou seja, alguma etiqueta, legenda, imagem não genérica para distinguir e procurar semelhanças entre os vários infográficos (objetos visuais) e visualizações.

Porém, o crescimento contínuo desta rede social visual aponta em direção a um futuro promissor para estes recursos, tanto como uma ferramenta pedagógica para usar nas aulas visuais oferecidos aos estudantes, como para pesquisa de cunho em cultura visual digital com fins informativos, seja na área de infográficos ou de obras artísticas, como quisemos demonstrar. Apesar do tempo despendido na curadoria dos objetos visuais, o investimento de tempo para conclusão da coleta de pins de interesse vale o resultado final, também pelo conhecimento obtido durante a navegação pela grande rede espiralar, exponencial de possibilidades que cada pin proporciona.

\section{Referências bibliográficas}

ABDALLA, M. C. B. O discreto charme das Partículas Elementares. Física na Escola, v.6, n.1. 2005.

BACHELARD, G. A água e os sonhos: ensaio sobre a imaginação da matéria. São Paulo: Martins Fontes. 1989.

BARDIN, L. Análise de Conteúdo. Lisboa: Edições 70. 2011.

BULCÃO, M. Bachelard: a noção de imaginação. Revista Reflexão, n.83/84, p.11-14. 2013.

CANABARRO, I. S. Fotografia e História: questões teóricas e metodológicas. Visualidades, v.13 n.1 p.98-125. 2015.

CANABARRO, M. M.; BASSO, L. O. Os professores e as redes sociais. RENOTE Revista Novas Tecnologias na Educação, v.11, n.1, p. 1-9. 2013.

CORAZZA, S. M. Currículo e Didática da Tradução: vontade, criação e crítica. Educação \& Realidade, Porto Alegre, v.41, n.4, p.1313-1335. 2016.

CORAZZA, S. M. Didática da tradução, transcriação do currículo (uma escrileitura da diferença). Pro-Posições, São Paulo, v.26, n.1, p.105-122. 2015.

CORAZZA, S. M. O que se transcria em educação? Porto Alegre: UFRGS, 2013. $226 \mathrm{p}$. 
EICHLER, T. Z. N. A Química vista Dalí: O Surrealismo e Surracionalismo no Ensino de Química. Porto Alegre: IQ/UFRGS, 2016. 52p. Trabalho de Conclusão de Curso em Licenciatura em Química.

FERRER, R. H. Gráficos que cuentan historias: caracterización de infografías y visualizaciones narrativas a traves de Pinterest. Obra Digital, n.9, 98-119. 2015.

GORRI, A. P.; SANTIN FILHO, O. Representação de Temas Científicos em Pintura do Século XVIII: Um Estudo Interdisciplinar entre Química, História e Arte. Química Nova na Escola. v.31, n.3, p.184-189. 2009.

MELLO, R. S., BOLL, C. I. Cultura Digital e Educação: desafios contemporâneos para a aprendizagem escolar em tempos de dispositivos moveis. RENOTE - Revista Novas Tecnologias na Educação, v.12, n.1, p.1-11. 2014.

MOREIRA, M. A. Um mapa conceitual sobre partículas elementares. Revista de Ensino de Física. v.11, p.114-129. 1989.

NOGUEIRA, H. G., PEREIRA, A. T. C. Elementos interativos de sites de redes sociais em sites de ensino-aprendizagem. In: Anais do Congresso Nacional de Ambientes Hipermídia para Aprendizagem, v.7, p.1-11, São Luiz, 2015.

OSTERMANN, F. Um Texto para Professores do Ensino Médio sobre Partículas Elementares. Revista Brasileira de Ensino de Física, v.21, n.3, setembro. 1999.

OWENS, T. Curating in the Open: A case for iteratively and openly publishing curatorial research on the Web. Curator: The Museum Journal, vol.59, n.4, p.427-442. 2016.

PAIVA, R. Gaston Bachelard: a imaginação da ciência, na poética e na sociologia. São Paulo: Annablume. 2005.

PAULA, D. F. O., CAMELO, M. B. Redes Sociais: O tumblr e suas práticas escolares. RENOTE - Revista Novas Tecnologias na Educação, v.10, n.1, p.1-10. 2012.

PEARCE, N.; LEARMONTH, S. Learning beyond the classroom: evaluating the use of Pinterest in learning and teaching in an introductory anthropology class. Journal of Interactive Media in Education, n.12, p.1-10. 2013.

PINHEIRO, L. A. Partículas Elementares e Interações fundamentais no Ensino Médio. Mestrado profissionalizante em Ensino de Física (Dissertação), Universidade Federal do Rio Grande do Sul, 2011.

SELWYN, N.; STIRLING, E. Social media and education...now the dust has settleds. Learning, Media and Technology, v.41, n.1, p.1-5. 2016

SIQUEIRA, M., PIETROCOLA, M., Como a Física de Partículas Elementares pode contribuir no ensino básico? Em: $O$ que são quarks, glúons, bósons de Higgs, buracos negros e outras coisas estranhas? São Paulo: Editora da Física, p.195209, 2012.

TAVARES, W., PAULA, H. C., PAUlA, A. P. P Comunicação e Interação no Ensino Através do Uso de Redes Sociais Virtuais. RENOTE - Revista Novas Tecnologias na Educação, Porto Alegre, v.11, n.3. 2013.

VICENTE, T. A. S. Metodologia da análise de imagens. Contracampo, n.4, p.147-158. 2000 . 